\title{
ベルト掛方程式から摩擦指数を求める一方法
}

\section{東京工業大学 久世栄一・古島昭雄 \\ ONE GRAPHICAL METHOD FOR OBTAINING THE FRICTIONAL INDEX FROM THE BELTING EQUATION}

By Eiichi Kuze aud Teruo Furushima

(Tokyo Institute of Technology, Ōokayama, Meguro-ku, Tokyo, Japan)

On the fibre or yarn sliding around a cylinder, the relation of the initial tension to the final tension is given by the following equation (i. e. belting equation):

$$
T^{1-N}=T_{0}^{1-N}+a(1-N) \theta \rho^{1-N}
$$

where

$T$ is the final tension of fibre or yarn,

$T_{0}$ is the initial tension of fibre or yarn,

$\theta$ is the lapping angle of fibre or yarn against the cylinder,

$\rho$ is the radius of the cylinder,

$N$ is the frictional index,

$a$ is the constant.

From the above equation, one method for calculating the approximate value of the frictional index is stated below.

1) The following equation is derived from the eqation (1):

$$
\log d T / d T_{0}=N \log \left(T / T_{0}\right)
$$

Let $x=\log \left(T / T_{0}\right)$ and $y=\log d T / d T_{0}$, then a graph having gradient $N$ and passing through the origin of the coordinate would be expected.

2) The method of the simplest calculation may be expressed by

$$
N=\sum y_{i} / \sum x_{i}
$$

where $x_{i}$ and $y_{i}$ are the values based on the experimental data.

3) The value of $d T / d T_{0}$ can be obtained by the gradient of two consecutive points given in the experimental data. Then a method for estimating the value of $T / T_{0}$ is to obtain the mean value of $T / T_{0}$ for the two consecutive points.

(Received June 9, 1964)

\section{1. まえがき}

瀻維または糸の単位長さに加方荷重 $R$ 亿封して摩擦 力 $F$ は $F=a R^{N}$ で表わされる。ここで $a, N$ は定数。し

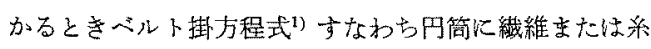
をべルト挂して滑らせたときの摩擦を表わす式は次のよ らに示される。

$$
T^{1-N}=T_{0}^{1-N}+a(1-N) \theta \rho^{1-N}
$$

ただ， $T$ 采の終張力

$T_{0}$ 系の初張力

$\theta$ 糸の円筒に対する巻きつけ角

$\rho$ 円筒半径

$N$ 摩擦指数

a 定数
上式に甜いて実験值 $T, T_{0}$ を得た場合, 摩擦指数 $N を$ 求 める計算法には次の 2 つがある。

1）任意のNを与杂てaのパラッキを求め，このバラ ッキを最小ならしめるような $N$ を求める最小二来法的や り方 (Howelli) 。

2) $N \simeq 1$ の場合次の近似式を用いる力法 (Howell1) および Rubenstein²)。

$$
T / T_{0}=\exp \left\{a\left(\rho / T_{0}\right)^{1-N} \theta\right\}
$$

さらに精確な值を欲する時はこの近似式によつてだいた いのNをつか子1）の方法による。1)の方法は相当の計 算量となり2）の方法では $N \simeq 1$ の場合の灭有効で市 る。これらとは異なつた方法を次に述べ。

2. 式の誘等と計算のやり方 


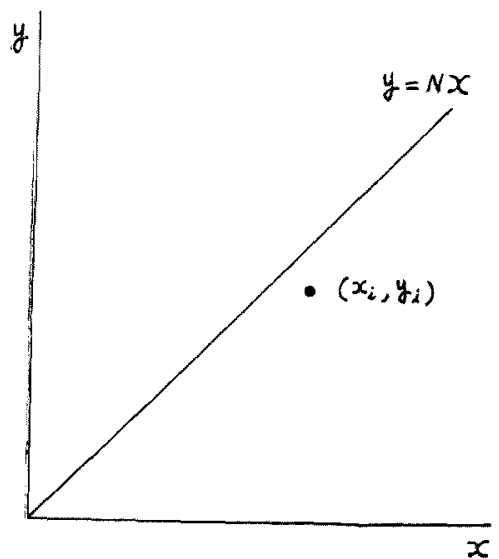

Fig. 1. The method of fitting. $x=\log \left(T / T_{0}\right), \quad y=\log d T / d T_{0}$

$x_{i}$ and $y_{i}$ are the values based on experimental data. Best fitting line is shown by $y=N x$.

\section{1）基本式の誘導}

ベルト掛方程式( 1 )微分なる上

$$
d T / d T_{0}=\left(T / T_{0}\right)^{N}
$$

※得る。よつ

$$
\log d T / d T_{0}=N \log \left(T / T_{0}\right)
$$

$\log d T / d T_{0}$ をy軸に $\log \left(T / T_{0}\right)$ を $x$ 韩にとると勾配 $N$ で原点通るグラフが得られるはずである。

また付着項がある場合"少なおり

$$
\left(T+R_{0} \rho\right)^{1-N}=\left(T_{0}+R_{0} \rho\right)^{1-N}+a(1-N) \theta \rho^{1-N}
$$

たたし $R_{0}$ は禾単位器さ当りの円筒への付着力

○場合性

$$
\log d T / d T_{0}=N \log \left(\overline{T+\overline{R_{0}} \rho} / \overline{T_{0}+R_{0} \rho}\right)
$$

任意の $R_{0} \rho$ をとることにより best fit させることが試 行錯詒によつてできる。

2) fitting のさせ方

$y=\log d T / d T_{0}, \quad x=\log \left(T / T_{0}\right)$ とし $x_{i}, y_{\ell}$ を艺れぞれ 実験によつて得られた值とする(Fig.1)。fitting のさせ

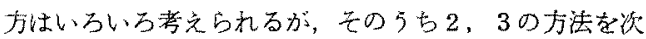
にらけ゚る。

i. 対数グラフにプロットし直锶的に fit させる。い わわる目のこによるち法。

ii. 平均的考炕よる方法。 $x_{i}$ の誤差に詨し $y_{i}$ の誤

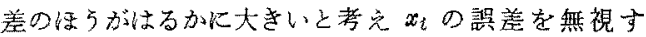

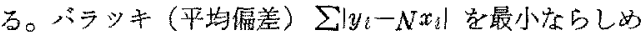
るようにさせる。すなわら

$$
N=\sum y_{i} / \sum x_{i} \pm t_{\alpha} \sqrt{n} / \sum x_{i} \cdot \sqrt{\left(\sum y_{3}^{2}-\sum^{2} y_{i} / n\right) /(n-1)}
$$

ただし n $\left(x_{i}, y_{i}\right)$ の数

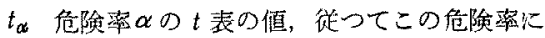
よる信頼限界が土以下の項によつて表わされ 万。

iii. 等等散性を仮定した最小二乗法。バシッキ

$\sum\left(y_{\imath}-N x_{\imath}\right)^{2}$ を最小ならしめるよらな $N$ を求めると

$N=\sum x_{i} y_{i} / \sum x_{i}^{2} \pm t_{\infty} \sqrt{n} / \sum x_{i}{ }^{2}$.

$$
\sqrt{\left(\sum x_{i}^{2} y_{i}^{2}-\sum^{2} x_{i} y_{i} / n\right) /(n-1)}
$$

iv. 等相対分散を仮定し大最小二乘法。バラッキ $\sum\left(y_{\imath}-N x_{i}\right)^{2} / x_{1}^{2}$ を最小ならしるるような $N$ 求める と

$$
N=\left(\sum y_{i} / x_{i}\right) / n \pm t_{\alpha} / \sqrt{n} .
$$$$
\sqrt{\left(\sum y_{i}^{2} / x_{i}^{2}-\sum^{2} y_{i} / x_{i} / n\right) /(n-1)}
$$

3) 部簤方法

$d T / d T_{0}$ は相となる2 点よりその勾配を求的ることに 上つて求めると，これに対応する $T / T_{0}$ の決方が問題 となる。これが本法において䛊差の入つてくる本䁈的問

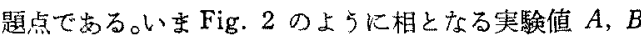

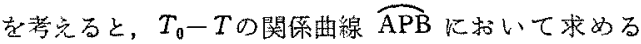
$T / T_{0}$ の值を $\overline{\mathrm{OP}}$ の勾配とすれば，A.Bの中点 $\mathrm{M}$ 上り 勾配 $\overline{\mathrm{OM}}$ 在求めるものと勾配 $\overline{\mathrm{OA}}$ と $\overline{\mathrm{OB}}$ の平均 $\overline{\mathrm{O}}$ 学 求めるものとが考觉られる。 $\overline{\mathrm{OP}}$ は $\overline{\mathrm{AB}}$ の勾配之 $\overparen{\mathrm{APB}}$ の放ん曲の変化のぐあいから $\overline{\mathrm{OM}}$ より O-T 韩よりにな る。また $\overline{\mathrm{O}} \mathrm{D}$ も同様である。一方計算の手間は $\overline{\mathrm{OD}}$ のほ

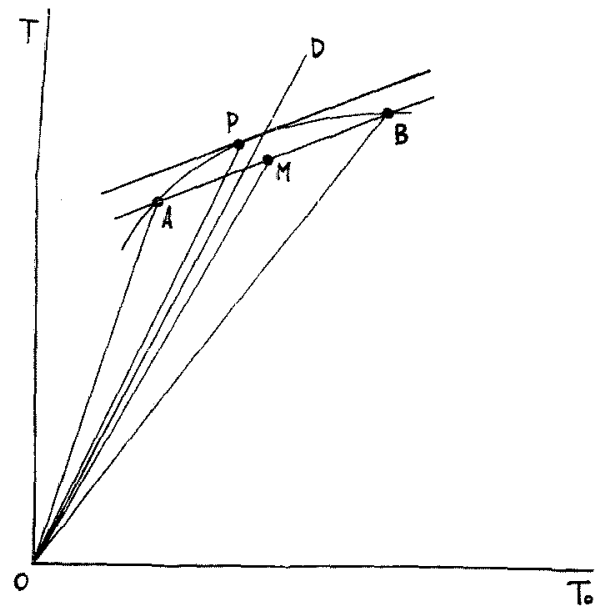

Fig. 2. A method for estimating the values of $T$ / $T_{0} . \quad A$ and $B$ are experimental points and $\widehat{\mathrm{APB}}$ is $T-T_{0}$ curve. Ideal value of $T / T_{0}$ is shown by the gradient of OP. $M$ is the point of centre between $A$ and $B$, and the $\mathrm{gr}$ adient of $\overline{O D}$ is the mean of the gradients $\overline{O A}$ and $\overline{O B}$, Then $\overline{O D}$ is nearer to $\overline{O P}$ than $\overline{O M}$. 
Table 1. An example of the calculation for $N=1$, from Rubenstein's data. $100 / 36 / 4$ continuous filament viscose (11.1 tex) lapping around a rough glass rod and sliding at speed $32 \mathrm{~cm} / \mathrm{sec}$.

\begin{tabular}{|c|c|c|c|c|c|c|}
\hline$T_{0} \mathrm{~d}$ & erence & $T$ & difference & $d T / d T_{0}$ & $T / T_{0}$ & mean of $T / T_{0}$ \\
\hline $6.0 \mathrm{~g}$ & & 13.7 & 70 & & 2.28 & \\
\hline 9.5 & & 21.6 & 8.9 & 2.25 & 2.27 & 2. 28 \\
\hline 12.5 & 3.0 & 28.2 & 6.6 & 2.20 & 2.26 & 2.26 \\
\hline 16.5 & 4.0 & 36.7 & 8.5 & 2.12 & 222 & 2.24 \\
\hline 21.5 & 5.0 & 47.3 & 10.6 & 2.12 & 220 & 2.21 \\
\hline 25.0 & 3.5 & 55.5 & 8.2 & 2. 34 & 2.22 & 2.21 \\
\hline 30.0 & 5.0 & 64.9 & 9.4 & 1.88 & 2. 16 & 2.19 \\
\hline
\end{tabular}

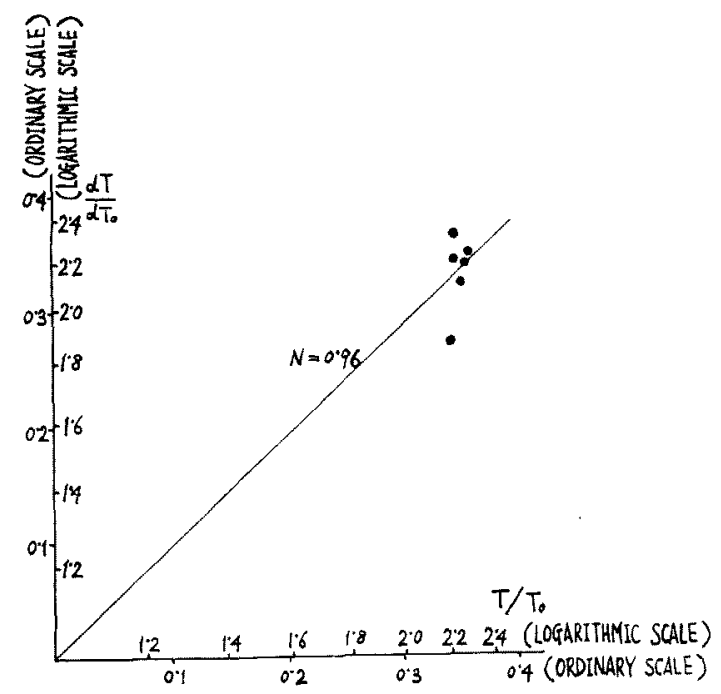

Fig. 3. Graphical demonstration of Table 1.
らが一段階少ない。いずれにしても その差は僅少であうう。よつて OA， $\overline{\mathrm{OB}}$ の勾配の平均加ら $T / T_{0}$ 艺推定 することにする。

往つて本埌を用いるときは打点数 を多くする使らが個々の点の精度を 上げるよりもよいことになる。

\section{3. 計 算 例}

1) 摩搖指数が $N$ K近い場合の言 算例を Rubenstein ${ }^{2)}$ の実験結果よ 9 Table 1 款上び Fig. 3 亿例示 可る。

$N$ が1飞近い場合は打点は1力所 に集中して表われるが，グラフは原 点を通る性質を持つているので勾配 の精度には影響しないのが本法の特 徽である。

2) 摩擦指数 $N$ がー一般に表方れる ような健の場合についての計算例を Lyne ${ }^{4)}$ の実験結果より Table 2 招 よび Fig. 4 に示す。

平均的考光による計算值は 0.777 等分散を仮定した最小二乘法による ものは 0.785 そして等相坟分散を

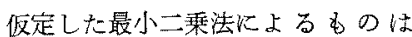
$0.770 \pm 0.045$ (95\%共頼限界) となっ た。一方 Howell の最小二乗法的也 り力で $a$ のすなわち $a(1-N) \theta \rho^{1-N}$ の相対分散を $N=0.78 ， 0.79 ， \quad 0.80$

Table 2. An example of the calculation for general value of $N$, from Lyne's data. Continuous filament yarn made of cellulose acetate, lapping around a chromium plated cylinder and sliding at speed $100 \mathrm{~m} / \mathrm{min}$.

$$
N=\sum y_{i} / \sum x_{t}=4.592 / 5.904=0.78 \text {. }
$$

\begin{tabular}{|c|c|c|c|c|c|c|c|c|}
\hline$T_{0}$ & difference & $T$ & difference & $d T / d T_{0}$ & $\log d T / d T_{0}$ & $T / T_{0}$ & mean of $T / T_{0}$ & $\log \left(\right.$ mean of $\left.T / T_{0}\right)$ \\
\hline $1 \mathrm{~g}$ & 1 & 8.3 & 6.0 & 6.00 & 0.778 & 8.30 & 7.72 & 0.888 \\
\hline 2 & 3 & 14.3 & 13.9 & 4.64 & 0.110 & 7.15 & 6.40 & 806 \\
\hline 5 & 2 & 28.2 & 6.9 & 3.45 & 538 & 5.64 & 5.32 & 726 \\
\hline 7 & 3 & 35.1 & 9.6 & 3. 20 & 505 & 5.01 & 4.74 & 676 \\
\hline 10 & 5 & 44.7 & 15.4 & 3.08 & 489 & 4.47 & 4. 24 & 627 \\
\hline 15 & 5 & 60.1 & 14.3 & 2.86 & 456 & 4.01 & 3.87 & 588 \\
\hline 20 & 5 & 74.4 & 12.9 & 2.58 & 412 & 3.72 & 3.60 & 556 \\
\hline 25 & 5 & 87.3 & 12.4 & 2.48 & 395 & 3. 49 & 3.41 & 533 \\
\hline 30 & 10 & 99.7 & 22.5 & 2.25 & 352 & 3.32 & 3.19 & 504 \\
\hline 40 & & 122.2 & & & & 3. 05 & & \\
\hline
\end{tabular}




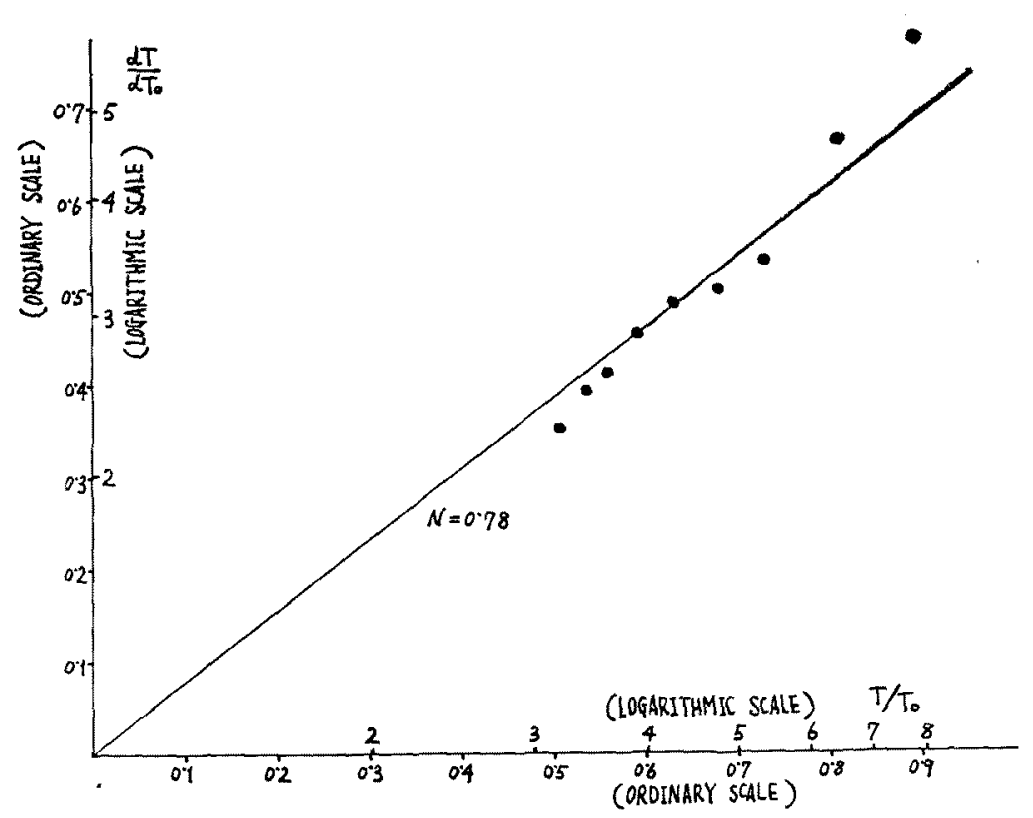

Fig. 4. Graphical demonstration of Table 2.

について調ベるとその値 は $8.4 \times 10^{-4}, 6.7 \times 10^{-4}$ $7.1 \times 10^{-4}$ となつた。よ つて本法による場合は目 のこ炕平均的考点に

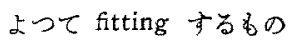
で充分なるのと考えられ る。さらに精密な値がは しい昜合は Howell の力 法によらね将ならないだ 350

3) 付着項のむる場合 のデータ Table $3 a$ より (4)式の $R_{0} \rho$ K適当な 偩を入れて平均偏差を最 小ならしめる方法で， best fit 竟得た場合の計 算例を Fig. 5 に示す。 各 $R_{0} \rho$ の便儿対する偏差 D和 $\sum\left|y_{1}-N x_{i}\right| \measuredangle N \omega$ 蒀竟 Table $3 b$ 儿示す。

$N=0.75$ が求める值でする。

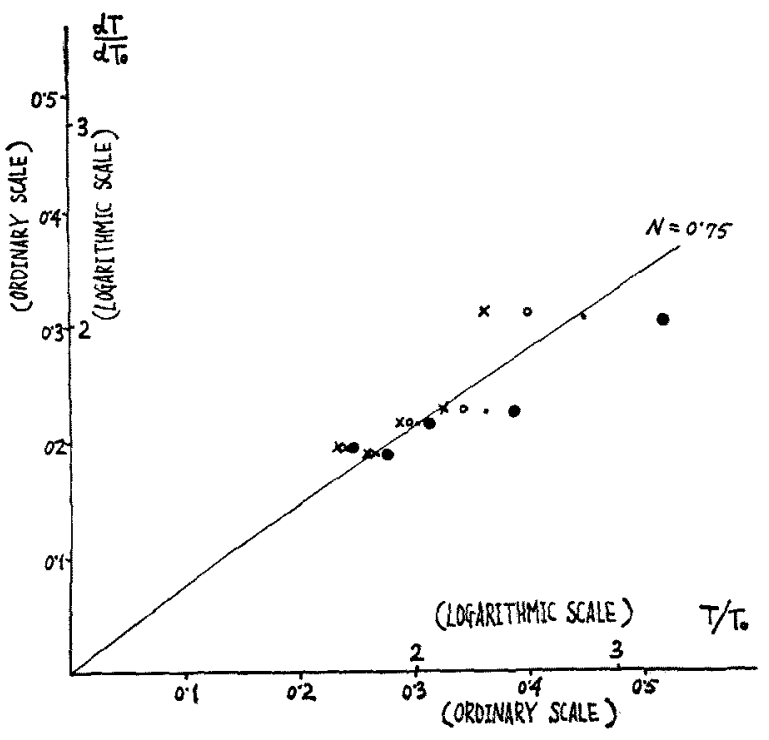

Fig. 5. Graphical demonstrations of Table 3 a with the variable values of $R_{0} \rho$.

$\begin{array}{rrr}- & R_{0} \rho=0 \mathrm{mg} \text { i.e. } N=0.70 \\ 0 & 5 & 0.75 \\ \times & 10 & 0.79 \\ & 15 & 0.82\end{array}$

The best fit value is $N=0.75$.
Table 3a. Experimental data of initial tension and final tension for Tetoron (polyester) $5 \mathrm{~d}(555$ $m$ tex) sliding on a mat fin. ished $16 \mathrm{~mm} \phi$ cylinder with speed $120 \mathrm{~cm} / \mathrm{min}$.

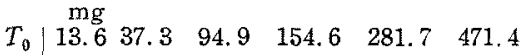
\begin{tabular}{l|llllll}
$T$ & 50 & 100 & 200 & 300 & 500 & 800
\end{tabular}

Table $3 \mathrm{~b}$. Values of cohesion term $R_{0} \rho$ and of frictional index $N$ with variance $\sum\left|y_{t}-N x_{i}\right|$.

The best fitted value is $N=$ 0.75 or $R_{0} \rho=5 \mathrm{mg}$.

\begin{tabular}{ccc}
$R_{0} \rho$ & $N$ & $\sum\left|y_{i}-N x_{t}\right|$ \\
\hline $0 \mathrm{mg}$ & 0.70 & 0.10 \\
5 & 0.75 & 0.05 \\
10 & 0.79 & 0.07 \\
15 & 0.82 & 0.09
\end{tabular}

4. ま め

ベルト排力程式

$T^{1-N}=T_{0}^{1-N}+a(1-N) \theta \rho^{1-N}$

ただし $T$ 糸の終張力

$T_{0}$ 系の初張力

$\theta$ 糸の円筒に対する巻付角 
(15)

\section{$\rho$ 円筒半径 \\ $N$ 摩摖指数 \\ $a$ 定数}

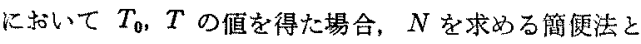
して次の方法を開哞した。すなるる相となる $T_{0}, T$ の 2 つの点より勾配 $d T / d T_{0}$ を得, これに対灾する $T / T_{0}$ の值としてこの 2 点の $T / T_{0}$ の值を求め, これを平坞す る。これより

$$
\log d T / d T_{0}=N \log \left(T / T_{0}\right)
$$

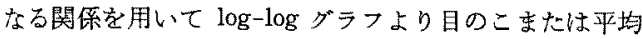
によつて $N$ を求的るこどできる。

$$
\text { 5. あとがき }
$$

i. 計算が簡便である。

ii. グラフより面観的な判断ができる。

iii、任意のNの值の場合に適用できる。

iv. 計算值の精度を上げるためには個々の点の精度 を上げるよりる打点数を多くすべきである。

v.さらに精密にはHowell11) の最小二乗法的やり方 によらねばならないが，一般に性本法で充分だろう。 文献

1) H. G. Howell ; J. Text. Inst., 44, T 359 (1953)

2) C. Rubenstein; J. Text. Inst., 49, T 181 (1958)

3) 久世, 古岛; 本誌投稿中

4) D. G. Lyne ; J. Text. Inst., 46, P 112 (1955)

本法の特致などをあげると 